\title{
Resilience in Individuals at Clinical High Risk for Psychosis
}

\author{
Susana Marulanda ${ }^{1}$ and Jean Addington ${ }^{2}$ \\ ${ }^{1}$ Department of Psychology, University of Calgary, Calgary, Alberta, Canada \\ ${ }^{2}$ Hotchkiss Brain Institute, Department of Psychiatry, University of Calgary
}

\section{Abstract}

Background-It has been suggested that resilience may be a protective factor with respect to mental illness. This may be an important factor for those who are vulnerable to psychiatric illness. Thus, the aims of this paper were to compare levels of resilience between individuals at clinical high risk (CHR) for psychosis and healthy controls, and to examine associations between resilience and clinical measures, functioning, and trauma of CHR participants.

Method-Eighty participants, $40 \mathrm{CHR}$ and 40 University of Calgary undergraduate students, completed two resilience questionnaires: the Connor-Davidson Resilience Scale and the Child and Youth Resilience Measure.

Results-A t-test revealed a significant difference between the groups on levels of resilience $(\mathrm{t}=4.34, \mathrm{p}<0.01)$, demonstrating that CHR participants have lower levels of resilience than healthy controls. In terms of the associations between resilience and measures of mental health of CHR participants, it was found that higher levels of resilience were related to lower negative symptoms, depression, and anxiety. Furthermore, resilient CHR participants showed higher levels of role functioning and generally reported higher positive schemas of self and others, as well as lower stress to reported life events. No associations were found between resilience and attenuated psychotic symptoms, social functioning, IQ, and trauma.

Conclusions-The results of the current study suggest that resilience may be beneficial to other mental issues present in CHR individuals but this may not be the case for attenuated psychotic symptoms.

\section{Keywords}

clinical high risk; psychosis; resilience; prodrome; risk

\begin{abstract}
Reliable criteria have been developed to prospectively identify people 'at-risk' for psychosis and thus experiencing a potential prodrome for this illness. ${ }^{1}$ Since the criteria for being at risk are mainly based on attenuated psychotic symptoms, the term clinical high-risk (CHR) is used to describe this population. In addition to attenuated symptoms, comorbid diagnoses, poor cognition, and poor functioning have also been reported in this group. ${ }^{2}$ A recent metaanalysis $^{3}$ indicates that approximately $29 \%$ of these young people meeting an at-risk
\end{abstract}

*Corresponding Author: Dr Jean Addington, Mathison Centre for Mental Health Research and Education, University of Calgary, 3280 Hospital Drive NW, Calgary, Alberta T2N 4Z6 Canada. jmadding @ucalgary.ca. 
syndrome will go on to develop a full-blown psychotic illness within two years. Even those who do not make the transition to psychosis may continue to have fluctuating subthreshold symptoms and poor functioning. ${ }^{4}$ In addition, high rates of childhood trauma have been reported, ${ }^{5,6}$ as well as experiences of major life stressors. ${ }^{7}$

The possible relationship between life stress and mental health issues has led to the consideration of resilience as an important factor for the promotion of good mental health. ${ }^{8}$ For example, although some individuals never recover from traumatic experiences, resilient individuals may experience only transient disturbances in their normal functioning and, over time, continue to demonstrate the capacity for positive emotions. ${ }^{9}$ Resilience is considered to be a protective factor that fosters a positive outcome among people facing adverse circumstances. ${ }^{10}$ It can include personality traits, social skills, or coping mechanisms. A recent definition of resilience is the outcome of the interactions between individuals and their environment, and the processes that contribute to these outcomes. ${ }^{11}$ Thus, the individual's ability to engage in health enhancing resources, such as education and community involvement, and the provision of such resources by the environment, can equally contribute to the healthy outcome of the individual.

Recent research in depression, anxiety, and post-traumatic stress disorder has demonstrated that resilience positively moderates depressive symptoms, negative affect, and perceived stress. ${ }^{12,13,14}$ It has also been reported that individuals with schizophrenia who are in remission have significantly higher resilience scores. ${ }^{15}$ Resilience has not been addressed in the CHR population and it may be valuable to understand the role of resilience on the mental health outcome of this vulnerable population.

The aims of this study were to compare CHR participants and healthy controls on levels of resilience, and to examine the relationship between resilience and symptoms, functioning, and past stressors in CHR individuals. We predicted that participants at CHR would have lower levels of resilience relative to healthy controls, and that lower levels of resilience in this population would be associated with increased severity of positive and negative symptoms, depression, anxiety, negative self-schemas, lower social and role functioning, as well as increased past trauma and life events.

\section{METHODS}

\section{Participants}

The sample consisted of 40 CHR participants (22 male, 18 female) recruited from a longitudinal study of predictors of psychosis at the University of Calgary. All CHR participants were required to meet the Criteria of Prodromal Syndromes (COPS) according to the Structured Interview for Prodromal Syndromes (SIPS). ${ }^{1}$ Participants were excluded if they met criteria for a current or lifetime axis I psychotic disorder, prior history of antipsychotic treatment, an intelligence quotient less than 70, or past or current history of a clinically significant central nervous system disorder. Recruitment has been described in detail elsewhere. ${ }^{16}$ 
The control group was comprised of 40 psychology undergraduate students (21 males, 19 females) from the University of Calgary. These participants were recruited using the Psychology department's Research Participation System (RPS), an online tool for managing research studies involving Psychology students. As part of the RPS requirements, all participants were awarded 0.5 research credits towards an undergraduate psychology course for their participation. Control participants were screened for attenuated psychotic symptoms using the Prime Screen Revised (PS-R) ${ }^{17}$ and were excluded from the study if they had a rank of 4 or over on this scale. This rank was achieved if participants either: (a) selected one or more "definitely agree" response or (b) selected three or more "somewhat agree" responses.

\section{Measures}

The Structure Interview for Prodromal Syndromes (SIPS) and The Scale for Assessment of Prodromal Symptoms (SOPS) ${ }^{1}$ were used to determine criteria for a prodromal syndrome and to determine the presence and severity of prodromal symptoms. The Prime Screen Revised (PS-R) ${ }^{17}$ was used to assess the presence of prodromal symptoms in the control sample. The PS-R has high clinical construct validity and, compared to other measures, has an excellent sensitivity (100\%) and good specificity $(74 \%) .{ }^{17}$

Depression was assessed with the Calgary Depression Scale for Schizophrenia (CDSS), ${ }^{18}$ and anxiety with the Social Interaction Anxiety Scale (SIAS) and the Social Anxiety Scale (SAS). ${ }^{19}$ The Brief Core Schema Scale (BRSS) ${ }^{20,21}$ was used to measure negative and positive evaluations of self, as well as positive and negative evaluations of others. Functioning was assessed with the Global Functioning Scale: Social and Role, which is specifically designed to measure functioning in individuals in the prodromal phase of psychosis. $^{22}$

Trauma was assessed using the Childhood Trauma and Abuse scale, ${ }^{23}$ a semi-structure interview to obtain information on emotional, physical, psychological or sexual abuse occurring before the age of 16. The Psychiatric Epidemiology Research Interview Life Events Scale ${ }^{24}$ was also used to assess trauma. This scale is a 102 -item scale used to measure stressful life events experienced by participants within the last year. Two score are obtained from this scale: the total number of life events experienced, and the sum of the participant's stress rating for each event.

Several scales exist to measure resilience but all have some shortcomings in terms of their psychometric properties. ${ }^{25}$ Based on this review we used two measures to assess resilience: the Connor-Davidson Resilience Scale (CD-RISC), ${ }^{26}$ and the Child and Youth Resilience Measure (CYRM). ${ }^{27}$ The CD-RISC is a well-established measure of resilience, used mainly in adult populations. It consists of 25 items rated on a 5-point scale and assesses personal competence, tolerance to stress, acceptance of change and secure relationships, control, and spiritual influences. The total score ranges from 0-100, with higher scores reflecting greater resilience. The CD-RISC demonstrates high construct validity, as well as high internal consistency, with a Cronbach's alpha between 0.70 and $0.95 .{ }^{25}$ Furthermore, its levels of responsiveness have been validated through its association with global improvement in individuals suffering from post-traumatic stress disorder (PTSD) after a drug intervention. ${ }^{26}$ 
The CYRM is a 28 -item questionnaire rated on a 5-point scale. It was developed for use with youth ages 12-23 years that face significant adversity. ${ }^{28}$ Resilience is measured across four domains: individual, relational, communal, and cultural. ${ }^{27}$ The individual domain reflects personal and social skills, the relational domain measures relationships with parents or primary caregivers, communal items measure relationships with peers and mentors, and the cultural domain reflects environmental characteristics that contribute to resilient outcomes. Together, these domains reflect the definition of resilience as a dynamic interaction between the individual and the available resources in its environment. ${ }^{29}$ The total score on this scale ranges from 28-140. In terms of psychometric properties, the CYRM has high levels of content validity ${ }^{25}$ and internal consistency. ${ }^{30}$

\section{Procedures}

This study was approved by the Conjoint Health Research Ethics Board. All participants provided informed consent for the current study. For participants under the age of 18, parental consent was obtained from parents or guardians. Before completing the CD-RISC and the CYRM, controls were screened for current or past attenuated positive psychotic symptoms using the Prime Screen Revised (PS-R). For the CHR participants, completion of the resilience measures was done at their routine assessment. Participants were assigned a clinical rater who conducted semi structured interviews. Raters were experienced research clinicians who demonstrated adequate reliability at routine reliability checks. Gold standard post-training agreement on determining the prodromal diagnoses was excellent (kappa=0.90).

\section{Statistical Analyses}

Chi-square and t-tests were used to compare groups on demographics and resilience. For CHR individuals, Pearson correlations were used to determine associations between resilience and prodromal symptoms, depression, anxiety, schemas, functioning, IQ, and life events. Spearman correlations were used to compare resilience scores with trauma in CHR participants.

\section{RESULTS}

\section{Demographic characteristics}

The majority of the participants were male $(n=43,53.8 \%)$, Caucasian $(n=54,67.5 \%)$, and single (95\%). The groups did not differ in gender (22 males in the CHR group, 21 males in the control group). There were no racial differences between controls and CHR (9,3 Asian, 25,29 white, 6,8 mixed race, respectively). The control group (19.13 years, $\mathrm{SD}=1.36$ ) were significantly older $(\mathrm{t}=4.34, \mathrm{p}<0.01)$ than the CHR group $(17.05$ years, $\mathrm{SD}=2.69)$. It is difficult to compare the two groups on education as all of the controls had completed high school but not college or university. whereas the CHR group consisted of 27 who had not completed high school (22/27 were 17 years or younger, 11 had completed high school and 2 had completed college. 


\section{Associations between resilience scales}

Some associations were observed between the subscales of the CD-RISC and the CYRM suggesting some overlap. In addition, statistically significant correlations were found between the total scores of the two scales $(r=0.72, p<0.01)$. See Table 1.

\section{Group comparisons on resilience}

Significant differences were found for all sub-scores of the resilience measures, except for the Cultural sub-score of the CYRM and the Spiritual Influences sub-score from the CDRISC. Although there was a significant difference between the groups in terms of age, across measures of resilience, the effect of age was not significant. See Table 2.

\section{Associations between resilience and clinical measures}

For the CD-RISC, low levels of resilience were related to high levels of negative symptoms, negative self-schemas, and poor role functioning. For the CYRM, low levels of resilience were related to negative symptoms, depression, anxiety, negative schemas, poor role functioning, and higher number of life events and stress associated with them. See Tables 3 and 4.

\section{DISCUSSION}

To our knowledge, this study is the first to examine the role of resilience in individuals at CHR for psychosis. Two different scales were used to measure resilience. The total scores of the CD-RISC were highly correlated with those of the CYRM. Furthermore, in terms of the sub-scores, strong correlations were found between all of the sub-scores, except for Cultural and Spiritual Influences, which may be unique to each scale. Consistent with the first hypothesis, significant differences were found between CHR participants and healthy controls in their levels of resilience. CHR participants scored significantly lower than healthy controls on both resilience scales.

The second hypothesis of the study was that lower levels of resilience would be associated with an increased severity of positive and negative symptoms, depression, anxiety, high negative schemas of self and others, and poorer social and role functioning. This hypothesis was partially supported. Resilience was not associated with attenuated positive symptoms but was consistently associated with negative symptoms. This suggests that the risk for the development of psychosis continues to be present despite the resilience levels of the individual. It is possible that poor resilience contributes to the development of negative symptoms. Alternatively, the association between low levels of resilience and high levels of negative symptoms suggests that negative symptoms may be a barrier to the development of resilience. Negative symptoms, such as withdrawal and blunted affect, are present in the early stages of psychosis, and are argued to impede the development of interpersonal relationships. ${ }^{31}$ It is possible that CHR individuals presenting with higher levels of negative symptoms would be less able to take part in the building of secure relationships, which are a fundamental aspect of resilience, as they facilitate access to resources in the community, as well as address a need for comfort, trust, and a sense of belonging. ${ }^{29}$ 
Increased levels of anxiety and depression were associated with lower levels of resilience but mainly as measured by the CYRM. The CYRM emphasizes the importance of an individual's secure relationships and ties to the community in sustaining their wellbeing. ${ }^{29}$ Thus, it is possible that high scores on this measure are indicative of higher perceived and actual social support, which has been shown to be mitigating factors for depression and anxiety. ${ }^{32,33,34}$

High levels of resilience in CHR individuals were associated with higher positive and lower negative beliefs of self and others. This is consistent with the understanding of resilience as encompassing personal qualities that enable individuals to thrive in the face of adversity. ${ }^{26}$ It is possible that CHR individuals with high resilience scores would be more likely to endorse items on the Brief Core Schema Scale that are consistent with positive beliefs and reflect personal strength, such as 'I am successful', as well as more likely to believe themselves as being perceived positively by others, which may be a reflection of the social support present in their lives.

Findings show that higher levels of resilience measured on both scales were correlated with higher role functioning but unrelated to social functioning. It may be that individual characteristics, a psychosocial support system, and high positive emotionality present in resilient individuals aids in maintaining their roles in society despite the presence of adverse circumstances. ${ }^{35,36}$ Although these findings were unexpected due to the primary role that secure relationships play in resilience, ${ }^{27,37}$ it may be that the social functioning scale did not really tap in detail into relationships.

The third hypothesis of the study was that for CHR participants, lower levels of resilience would be associated with increased past trauma and life events. Despite evidence of increased trauma in this population,, 5 and previous studies showing an association between lifetime traumatic exposure and lower resilience scores, ${ }^{38,39}$ no associations were found between resilience and trauma in the present study. However, there was a significant relationship between resilience on the CYRM and life events, as measured by the PERI Life Events Scale. These associations were present for both, the number of stressful life events experienced and the perceived stress associated with them $(-0.32, \mathrm{p}<.05)$. This finding is consistent with previous research on resilience that suggests that active coping strategies used by resilient individuals make stressful life events seem less threatening, and thus easier to cope with. ${ }^{40}$

In summary, both resilience scales differentiated CHR participants and healthy controls on levels of resilience. The CYRM may be more useful in this CHR population since it was designed and has been tested in youth. It may also be more sensitive to the difficulties typically reported by this at-risk population and potentially allow for the personalization of interventions. Interventions aimed at promoting resilience can be helpful in improving the functioning of CHR individuals in society by decreasing feelings of anxiety, depression, and negative symptoms, promoting positive beliefs of self and others, and reducing stress reactivity to life events. Furthermore, resilience interventions, particularly those that promote social support, can also have a positive impact on mental health by encouraging health-seeking behaviours. According to research, ${ }^{41,42}$ greater levels of social support 
predict willingness to seek help. This may be because peers and family can recognize the need for the individual to seek help or may even intervene on their behalf during times of significant distress.

\section{Limitations}

There were limitations to this study. The sample size was relatively small and both were samples of convenience. It is likely that the controls had more education as they were limited to University of Calgary undergraduate students. Controls were significantly older than CHR participants. However, when investigated, it was found that resilience was unrelated to these age differences. Although the analysis was limited to carefully selected variables, the number of correlations performed might have resulted in a type I error. To protect from this risk it may have been appropriate to perform a Bonferroni's correction. However, because the study is exploratory in nature, this correction was deemed too strict as it was likely to limit any significant findings. Our results suggest a difference in resilience between CHR and healthy controls but we cannot make any definitive statement about its specificity. The lack of any clinical control in the study does limit our understanding of how specific compromised resilience factors are to those at CHR of psychosis and to what extent they are a general risk factor and characteristic of psychopathology. Regardless, the issue of addressing resilience in this group remains. Finally, due to the cross-sectional nature of the study, it is impossible to determine if resilience in this population changes over time and if it is related in any way to later conversion to psychosis.

\section{Conclusion}

In summary, results show that CHR individuals have lower levels of resilience compared to their healthy counterparts and that a relationship exists between resilience and mental health issues in CHR participants. Associations between resilience and lower levels of anxiety, depression, and negative symptoms suggest the role of resilience in maintaining the wellbeing of the CHR individuals despite the presence of attenuated positive symptoms. This is particularly evident in the relationships between levels of resilience and role functioning. Considering the benefits of resilience on the mental health of individuals at CHR for psychosis, further research should be done in order to develop interventions aimed at promoting resilience in this population.

\section{Acknowledgements}

This study was supported by the National Institute of Mental Health grant U01MH081984 to Dr Addington.

\section{REFERENCES}

1. McGlashan, TH.; Walsh, B.; Woods, S. The Psychosis-Risk Syndrome: Handbook for Diagnosis and Follow-up. New York, NY: Oxford University Press; 2010.

2. Addington J, Heinssen R. Prediction and prevention of psychosis in youth at clinical high risk. Annu Rev Clin Psychol. 2012; 8:269-289. [PubMed: 22224837]

3. Fusar-Poli P, Bonoldi I, Yung AR, et al. Predicting psychosis: meta-analysis of transition outcomes in individuals at high clinical risk. Arch Gen Psychiatry. 2012; 69:220-229. [PubMed: 22393215]

4. Addington J, Cornblatt BA, Cadenhead KS, et al. At clinical high risk for psychosis: outcome for nonconverters. Am J Psychiatry. 2011; 168:800-805. [PubMed: 21498462] 
5. Addington J, Stowkowy J, Cadenhead KS, et al. Early traumatic experiences in those at clinical high risk for psychosis. Early Interv Psychiatry. 2013; 7:300-305. [PubMed: 23343384]

6. Bechdolf A, Thompson A, Nelson B, et al. Experience of trauma and conversion to psychosis in an ultra-high-risk (prodromal) group. Acta Psychiatr Scand. 2010; 121:377-384. [PubMed: 20199494]

7. Miller P, Lawrie SM, Hodges A, Clafferty R, Cosway R, Johnstone EC. Genetic liability, illicit drug use, life stress and psychotic symptoms: preliminary findings from the Edinburgh study of people at high risk for schizophrenia. Soc Psychiatry Psychiatr Epidemiol. 2001; 36:338-342. [PubMed: 11606002]

8. Patel V, Goodman A. Researching protective and promotive factors in mental health. Int J Epidemiol. 2007; 36:703-707. [PubMed: 17646185]

9. Bonanno GA, Papa A, O’Neill K. Loss and human resilience. Appl Prev Psychol. 2001; 10:193206.

10. Bonanno GA. Loss, trauma, and human resilience: have we underestimated the human capacity to thrive after extremely aversive events? Am Psychol. 2004; 59:20-28. [PubMed: 14736317]

11. Ungar M. Nurturing hidden resilience in at-risk youth in different cultures. J Can Acad Child Adolesc Psychiatry. 2006; 15:53-58. [PubMed: 18392194]

12. Wingo AP, Wrenn G, Pelletier T, Gutman AR, Bradley B, Ressler KJ. Moderating effects of resilience on depression in individuals with a history of childhood abuse or trauma exposure. $\mathrm{J}$ Affect Disord. 2010; 126:411-414. [PubMed: 20488545]

13. Hoge EA, Austin ED, Pollack MH. Resilience: research evidence and conceptual considerations for posttraumatic stress disorder. Depress Anxiety. 2007; 24:139-152. [PubMed: 16892420]

14. Steinhardt M, Dolbier C. Evaluation of a resilience intervention to enhance coping strategies and protective factors and decrease symptomatology. J Am Coll Health. 2008; 56:445-453. [PubMed: 18316290]

15. Torgalsboen AK. Sustaining full recovery in schizophrenia after 15 years: does resilience matter? Clin Schizophr Relat Psychoses. 2012; 5:193-200. [PubMed: 22182456]

16. Addington J, McGregor L, Marulanda D, Raedler T. Recruitment strategies for the detection of individuals at clinical high risk of developing psychosis. Epidemiol Psychiatr Sci. 2012; 22:1-5. [PubMed: 23253139]

17. Kobayashi H, Nemoto T, Koshikawa H, et al. A self-reported instrument for prodromal symptoms of psychosis: testing the clinical validity of the PRIME Screen-Revised (PS-R) in a Japanese population. Schizophr Res. 2008; 106:356-362. [PubMed: 18809299]

18. Addington D, Addington J, Maticka-Tyndale E. Assessing depression in schizophrenia: the Calgary Depression Scale. Br J Psychiatry Suppl. 1993; 22:39-44. [PubMed: 8110442]

19. Olivares J, García-López LJ, Hidalgo MD. The social phobia scale and the social interaction anxiety scale: factor structure and reliability in a Spanish-speaking population. J Psychoeduc Assess. 2001; 19:69-80.

20. Fowler D, Freeman D, Smith B, et al. The brief core schema scales (BCSS): psychometric properties and associations with paranoia and grandiosity in non-clinical and psychosis samples. Psychol Med. 2006; 36:749-759. [PubMed: 16563204]

21. Addington J, Tran L. Using the Brief Core Schema Scales with Individuals at clinical high risk of psychosis. Behav Cogn Psychother. 2009; 37:227-231. [PubMed: 19364422]

22. Cornblatt B, Auther AM, Neindam T, et al. Preliminary findings for two new measures of social and role functioning in the prodromal phase of schizophrenia. Schizophr Bull. 2007; 33:688-702. [PubMed: 17440198]

23. Janssen I, Krabbendam L, Bak M, et al. Childhood abuse as a risk factor for psychotic experiences. Acta Psychiatr Scand. 2004; 109:38-45. [PubMed: 14674957]

24. Dohrenwend BS, Krasnoff L, Askenasy AR, Dohrenwend BP. Exemplification of a method for scaling life events: the Peri Life Events Scale. J Health Soc Behav. 1978; 19:205-229. [PubMed: 681735]

25. Windle G, Bennett KM, Noyes J. A methodological review of resilience measurement scales. Health Qual Life Outcomes. 2011; 9:8. [PubMed: 21294858]

26. Connor KM, Davidson JRT. Development of a new resilience scale: the connor-davidson resilience scale (CD-RISC). Depress Anxiety. 2003; 18:76-82. [PubMed: 12964174] 
27. Ungar M, Liebenberg L, Boothroyd R, et al. The study of youth resilience across cultures: lessons from a pilot study of measurement development. Res Hum Dev. 2008; 5:166-180.

28. Resilience Research Centre. The Child and Youth Resilience Measure-28: User Manual. Halifax, NS: Resilience Research Centre, Dalhousie University; 2009.

29. Ungar M, Brown M, Liebenberg L, et al. Unique pathways to resilience across cultures. Adolescence. 2007; 42:287-310. [PubMed: 17849937]

30. Daigneault I, Dion J, Hébert M, McDuff P, Collin-Vézina D. Psychometric properties of the child and youth resilience measure (CYRM-28) among samples of French Canadian youth. Child Abuse Negl. 2013; 37:160-171. [PubMed: 23260113]

31. Blanchard, JJ.; Panzarella, C. Affect and social functioning in schizophrenia. In: Mueser, KT.; Tarreir, N., editors. Handbook of Social Functioning in Schizophrenia. Needham Heights, MA: Allyn and Bacon; 1998. p. 181-196.

32. Liu DG, Wang SS, Peng RJ, et al. Interaction of social support and psychological stress on anxiety and depressive symptoms in breast cancer patients. Asian Pac J Cancer Prev. 2011; 12:2523-2529. [PubMed: 22320935]

33. Ye XQ, Chen WQ, Lin JX, et al. Effect of social support on psychological-stress-induced anxiety and depressive symptoms in patients receiving peritoneal dialysis. J Psychosom Res. 2008; 65:157-164. [PubMed: 18655861]

34. Evans, DL.; Foa, EB.; Gur, RE.; Hendin, H.; O'Brien, CP.; Seligman, M.; Walsh, T. Treating and Preventing Adolescent Mental Health Disorders: What We Know and What We Don't Know: A Research Agenda for Improving the Mental Health of Our Youth. New York, NY: Oxford University Press; 2005.

35. McMillan JH, Reed DF. At-risk students and resiliency: factors contributing to academic success. The Clearing House. 1994; 67:137-140.

36. Baumeister RF, Gailliot M, DeWall CN, Oaten M. Self-regulation and personality: how interventions increase regulatory success, and how depletion moderates the effects of traits on behavior. J Pers. 2006; 74:1773-1801. [PubMed: 17083666]

37. Ungar M. The importance of parents and other caregivers to the resilience of high-risk adolescents. Fam Process. 2004; 43:23-41. [PubMed: 15359713]

38. Campbell-Sills L, Forde DR, Stein MB. Demographic and childhood environmental predictors of resilience in a community sample. J Psychiatr Res. 2009; 43:1007-1012. [PubMed: 19264325]

39. Simeon D, Yehuda R, Cunill R, Knutelska M, Putnam FW, Smith LM. Factors associated with resilience in healthy adults. Psychoneuroendocrinology. 2007; 32:1149-1152. [PubMed: 17913377]

40. Tugade MM, Fredrickson BL. Resilient individuals use positive emotions to bounce back from negative emotional experiences. J Pers Soc Psychol. 2004; 86:320-333. [PubMed: 14769087]

41. Ciarrochi J, Deane FP, Wilson CJ, Rickwood D. Adolescents who need help the most are the least likely to seek it: the relationship between low emotional competence and low intention to seek help. Brit J Guid Couns. 2002; 30:173-188.

42. Sheffield JK, Fiorenza E, Sofronoff K. Adolescents' willingness to seek psychological help: promoting and preventing factors. J Youth Adolescence. 2004; 33:495-507. 


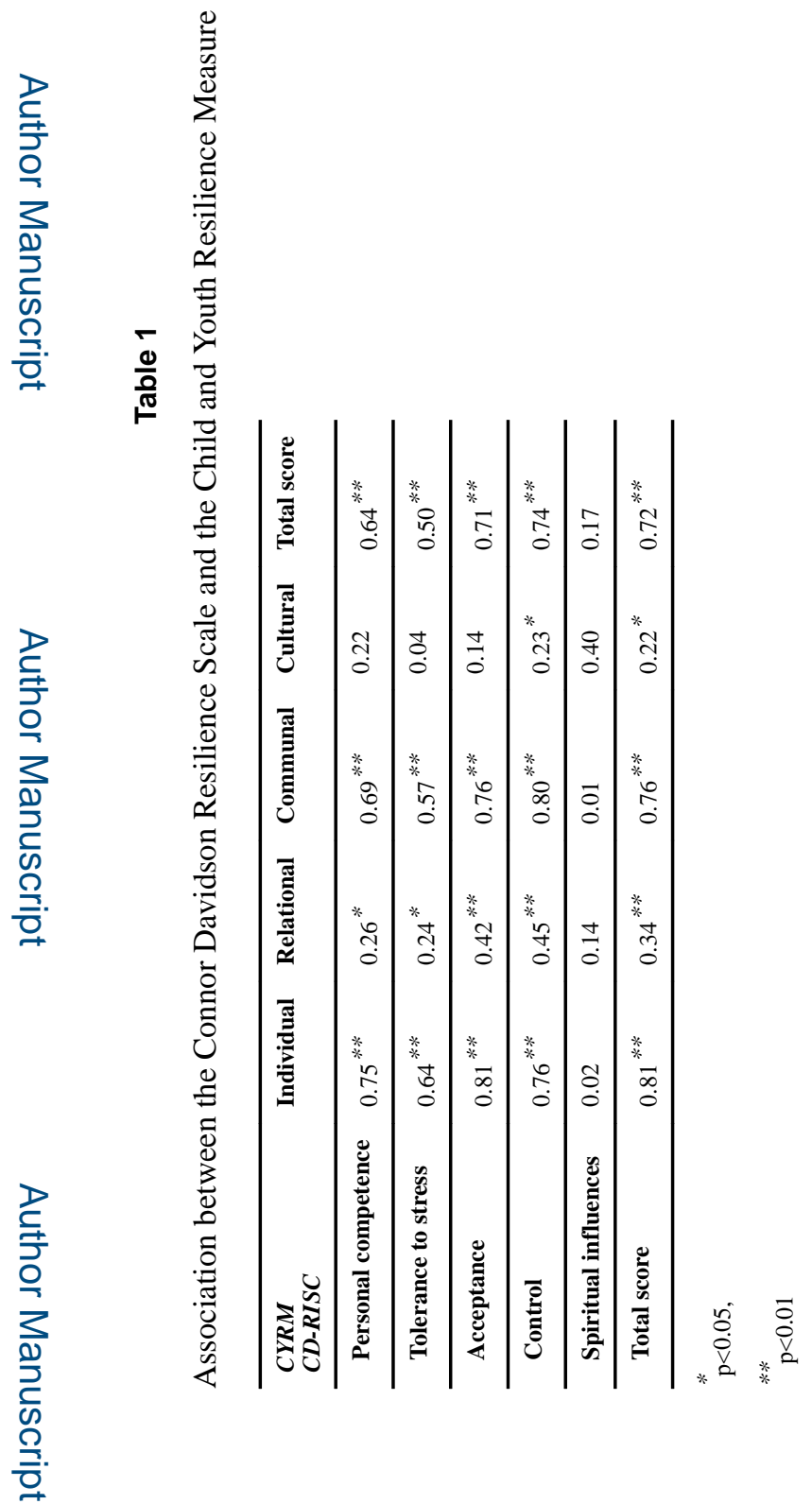

Early Interv Psychiatry. Author manuscript; available in PMC 2017 June 01. 
Table 2

Difference between CHR and Healthy Controls on Resilience Measures

\begin{tabular}{lcccc}
\hline Variable & Range & $\begin{array}{c}\text { CHR (n=40) } \\
\text { Mean (SD) }\end{array}$ & $\begin{array}{c}\text { Controls (n=40) } \\
\text { Mean (SD) }\end{array}$ & T value \\
\hline Connor Davidson & & & & \\
\hline Personal Competence & $0-32$ & $19.78(5.66)$ & $24.25(4.19)$ & $4.04^{* * *}$ \\
\hline Tolerance to Stress & $0-28$ & $16.15(5.17)$ & $19 / 01(4.03)$ & $2.79^{* * *}$ \\
\hline Acceptance to Change & $0-20$ & $13.08(3.11)$ & $15.65(2.34)$ & $4.17^{* *}$ \\
\hline Control & $0-12$ & $6.48(2.67)$ & $8.24(2.23)$ & $3.14^{* * *}$ \\
\hline Spiritual Influences & $0-8$ & $3.73(1.89)$ & $3.38(1.99)$ & -0.80 \\
\hline CD-RISC Total Score & $0-100$ & $59.20(14.99)$ & $70.57(11.47)$ & $3.81^{* * *}$ \\
\hline Child \& Youth Resilience Measure & & & & \\
\hline Individual Strengths & $8-40$ & $27.98(4.46)$ & $32.50(4.04)$ & $4.75^{* * *}$ \\
\hline Relational & $6-30$ & $18.60(4.51)$ & $21.22(3.74)$ & $2.83^{* * *}$ \\
\hline Communal & $8-40$ & $28.75(5.67)$ & $33.40(4.06)$ & $4.21^{* * *}$ \\
\hline Cultural & $6-30$ & $17.02(4.24)$ & $17.61(4.13)$ & 0.63 \\
\hline CYRM Total Score & $28-140$ & $92.34(14.02)$ & $104.73(12.80)$ & $4.12^{* * *}$ \\
\hline * $<0.05$, & & & & \\
***0.01 & & & & \\
p & & & & \\
\hline
\end{tabular}


急

을

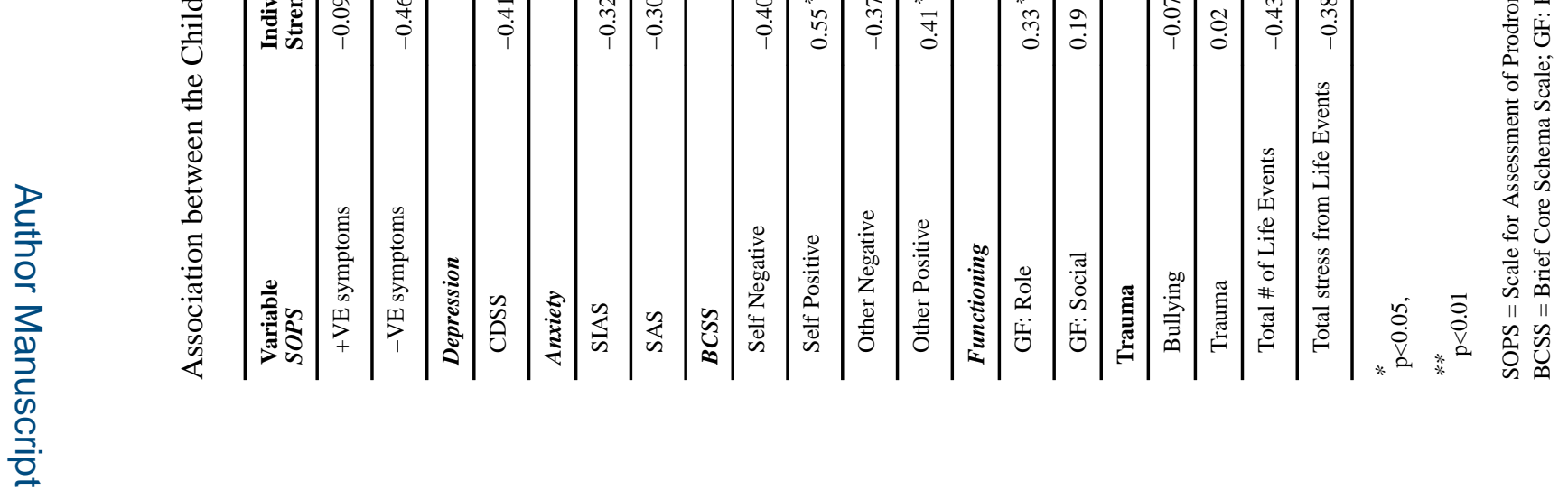

Early Interv Psychiatry. Author manuscript; available in PMC 2017 June 01. 